\title{
Disruption of Endogenous Purinergic Signaling Inhibits Vascular Endothelial Growth Factor- and Glutamate-Induced Osmotic Volume Regulation of Müller Glial Cells in Knockout Mice
}

\author{
Antje Grosche ${ }^{a}$ Thomas Pannicke ${ }^{b}$ Ju Chen ${ }^{d}$ Peter Wiedemann ${ }^{c}$ \\ Andreas Reichenbach ${ }^{b}$ Andreas Bringmann ${ }^{c}$ \\ ${ }^{a}$ Institute of Human Genetics, University of Regensburg, Regensburg, and ${ }^{b}$ Paul Flechsig Institute of Brain \\ Research and 'Department of Ophthalmology and Eye Hospital, University of Leipzig, Leipzig, Germany; \\ ${ }^{\mathrm{d}}$ Department of Medicine, University of California San Diego, La Jolla, Calif., USA
}

\section{Key Words}

Osmotic swelling · Müller cell · Vascular endothelial growth factor $\cdot$ Glutamate $\cdot$ Calcium

\begin{abstract}
Background/Aims: Osmotic swelling of Müller cells is a common phenomenon in animal models of ischemic and diabetic retinopathies. Müller cells possess a swelling-inhibitory purinergic signaling cascade which can be activated by various receptor ligands including vascular endothelial growth factor (VEGF) and glutamate. Here, we investigated whether deletion of $P 2 Y_{1}\left(P 2 Y_{1} R\right)$ and adenosine $A_{1}$ receptors $\left(A_{1} A R\right)$, and of inositol-1,4,5-trisphosphate-receptor type $2\left(\mathrm{IP}_{3} R 2\right)$, in mice affects the inhibitory action of VEGF and glutamate on Müller cell swelling. Methods: The crosssectional area of Müller cell somata was recorded after a 4-min superfusion of retinal slices with a hypoosmotic solution. Results: Hypoosmolarity induced a swelling of Müller cells from $P 2 Y_{1} R^{-/-}, A_{1} A R^{-/-}$and $I P_{3} R 2^{-/-}$mice, but not from wild-type mice. Swelling of wild-type Müller cells was induced by hypoosmotic solution containing barium chloride. Whereas VEGF inhibited the swelling of wild-type Müller cells, it had no swelling-inhibitory effect in cells from $A_{1} A R^{-/-}$ and $I P_{3} R 2^{-/-}$mice. Glutamate inhibited the swelling of wild-
\end{abstract}

type Müller cells but not of cells from $P 2 Y_{1} R^{-/-}, A_{1} A R^{-/-}$and $I P_{3} R 2^{-/-}$animals. Conclusion: The swelling-inhibitory effects of VEGF and glutamate in murine Müller cells is mediated by transactivation of $P 2 Y_{1} R$ and $A_{1} A R$, as well as by intracellular calcium signaling via activation of $\mathrm{IP}_{3} \mathrm{R} 2$.

Copyright $\odot 2013$ S. Karger AG, Base

\section{Introduction}

The presence of retinal edema is a major cause of visual impairment in ischemic-hypoxic and inflammatory retinopathies [1]. Edema develops by vascular leakage and/or dysfunctional fluid clearance from the retinal tissue [2]. One mechanism of fluid clearance involves water transport through Müller cells [3]. By transcellular water transport, Müller cells compensate osmotic gradients within the retinal tissue and across the gliovascular interface. Intense neuronal activity is associated with a decrease in extracellular fluid osmolarity [4]. In addition, the uptake of excess neuron-derived osmolytes (potassium, sodium glutamate) by Müller cells enhances the intracellular osmotic pressure in comparison to the extracellular fluid [5]. The osmotic imbalances are exacerbated under pathological conditions that are characterized by neuro-

\section{KARGER}

E-Mail karger@karger.com

www.karger.com/ore
(C) 2013 S. Karger AG, Basel

0030-3747/13/0504-0209\$38.00/0
Andreas Bringmann, $\mathrm{PhD}$

Department of Ophthalmology and Eye Hospital

University of Leipzig, Liebigstrasse 10-14

DE-04103 Leipzig (Germany)

E-Mail bria@medizin.uni-leipzig.de 
nal hyperexcitation. Moreover, a decrease in blood osmolality, e.g. during hyponatremia and hypoalbuminemia, represents a major pathogenic factor of retinal edema [6].

Under ischemic-hypoxic and inflammatory conditions, the transglial water transport is disturbed, as indicated by the alteration in the osmotic swelling characteristics of Müller cells. Under normal conditions, Müller cells do not swell for 10-15 min when retinal slices or freshly isolated cells are superfused with a hypoosmotic solution $[7,8]$. On the other hand, immediate swelling of Müller cells upon hypoosmotic challenge was observed in animal models of ischemic and inflammatory retinopathies including retinal ischemia reperfusion, diabetic retinopathy, retinal vein occlusion and ocular inflammation [9-12]. The change in the osmotic swelling characteristics of Müller cells suggests that the rapid water transport across Müller cell membranes is altered under pathological conditions. However, though intracellular edema of Müller cells caused by water accumulation within the cells was described to occur in animal models of ischemic and diabetic retinopathies [13,14], a swelling of Müller cells was rarely observed. This may suggest that endogenous mechanisms are present that inhibit the osmotic swelling of Müller cells under pathological conditions.

One mechanism that prevents osmotic swelling of Müller cells is the activation of an endogenous purinergic signaling cascade [15]. This cascade consists of the consecutive release of ATP and adenosine from Müller cells which activate purinergic $\mathrm{P} 2 \mathrm{Y}_{1}$ receptors $\left(\mathrm{P} 2 \mathrm{Y}_{1} \mathrm{R}\right)$ and adenosine $A_{1}$ receptors $\left(A_{1} A R\right)$, respectively $[8,16,17]$. Release of ATP is induced by activation of metabotropic glutamate receptors $[8,16,17]$. Vascular endothelial growth factor (VEGF) and various other receptor ligands including neuropeptide Y (NPY) and heparin-binding epidermal growth factor-like growth factor (HB-EGF) activate the volumeregulatory cascade upstream of glutamate release [16-19]. The final step of the cascade is the $\mathrm{A}_{1} \mathrm{AR}$-mediated opening of potassium and chloride channels in the Müller cell membrane; the rapid ion flux compensates the osmotic gradient across the membrane and, thus, prevents cellular swelling [15-17]. Disruption of the autocrine purinergic signaling in $\mathrm{P}_{2} \mathrm{Y}_{1} \mathrm{R}$ - and $\mathrm{A}_{1} \mathrm{AR}$-deficient mice results in rapid swelling of Müller cells under hypoosmotic conditions $[8,20]$. However, it is not known whether the swelling-inhibitory action of various receptor ligands besides ATP and adenosine is impaired in Müller cells of $P 2 Y_{1} R^{-/-}$and $A_{1} A R^{-/-}$ mice. Therefore, we determined the effects of VEGF and glutamate on the hypoosmotic swelling of Müller cells in retinal slices from wild-type, $P 2 Y_{1} R^{-/-}$and $A_{1} A R^{-/-}$mice. Because the swelling-inhibitory effect of ATP is dependent on intracellular calcium signaling mediated by the inositol1,4,5-trisphosphate-receptor type $2\left(\mathrm{IP}_{3} \mathrm{R} 2\right)[7,8]$, we also tested the effects of VEGF and glutamate on the osmotic swelling of Müller cells in retinal slices from $I P_{3} R 2^{-/-}$mice.

\section{Materials and Methods}

Materials

Human recombinant VEGF- $\mathrm{A}_{165}$ was purchased from Chemicon (Temecula, Calif., USA). Human recombinant HB-EGF, human recombinant NPY, 8-cyclopentyl-1,3-dipropylxanthine (DPCPX), (2S)-2-amino-2-[(1S, 2S)-2-carboxycycloprop-1-yl]-3-(xanth-9-yl) propanoic acid (LY341495), $N^{6}$-methyl-2'-deoxyadenosine- $3^{\prime}, 5^{\prime}$ bisphosphate (MRS2179), and all other agents used were from Sigma-Aldrich (Taufkirchen, Germany), unless indicated otherwise.

\section{Animals}

All experiments were done in accordance with the European Communities Council Directive 86/609/EEC, and were approved by the local authorities. Adult (2-6 months) animals of various mouse strains were used. Mice deficient in $P 2 Y_{1} R$ [21], $A_{1} A R$ and $\mathrm{IP}_{3} \mathrm{R} 2$, and littermate wild-type controls, were validated and characterized as described $[8,22,23]$. Müller cells of control mice from different strains did not differ in their swelling characteristics (not shown). Animals were maintained with free access to water and food in an air-conditioned room on a 12-hour light-dark cycle, and were killed with carbon dioxide.

\section{Preparation of Retinal Slices}

Pieces of freshly isolated retinas $(3 \times 3 \mathrm{~mm})$ were placed, with the photoreceptor side down, onto membrane filters (mixed cellulose ester, pore size: $0.45 \mu \mathrm{m}$; Schleicher \& Schuell MicroScience, Dassel, Germany). Retinal slices (thickness: $1 \mathrm{~mm}$ ) were cut from these tissues adhering to the membrane filters. The slices were transferred to recording chambers and kept submerged in extracellular solution. The chambers were mounted on the stage of an upright confocal laser scanning microscope (LSM 510 Meta; Zeiss, Oberkochen, Germany).

\section{Osmotic Swelling Experiments}

Swelling experiments were performed at room temperature $\left(20-23^{\circ} \mathrm{C}\right)$. To determine the volume changes of Müller cell somata evoked by hypoosmotic challenge, their cell bodies in the central part of the inner nuclear layer of retinal slices were recorded. To identify cell somata, retinal slices were loaded with the vital dye MitoTracker Orange ( $1 \mu \mathrm{M}$; Molecular Probes, Eugene, Oreg., USA) for $3 \mathrm{~min}$. Thereafter, the slices were continuously superfused with extracellular solution at a flow rate of $2 \mathrm{ml} / \mathrm{min}$. Recordings were made with an Achroplan $63 \times / 0.9$ water immersion objective (Zeiss). The pinhole was set at $151 \mu \mathrm{m}$; the thickness of the optical section was adjusted to $1 \mu \mathrm{m}$. MitoTracker Orange was excited at $543 \mathrm{~nm}$ with a HeNe laser, and emission was recorded with a 585-nm long-pass filter. The dye-filled somata were focused at the plane of their maximal extension.

A gravity-fed system with multiple reservoirs was used to perfuse the recording chamber continuously with extracellular solution; test substances were applied by changing the perfusate. The bathing solution in the recording chamber was totally changed 


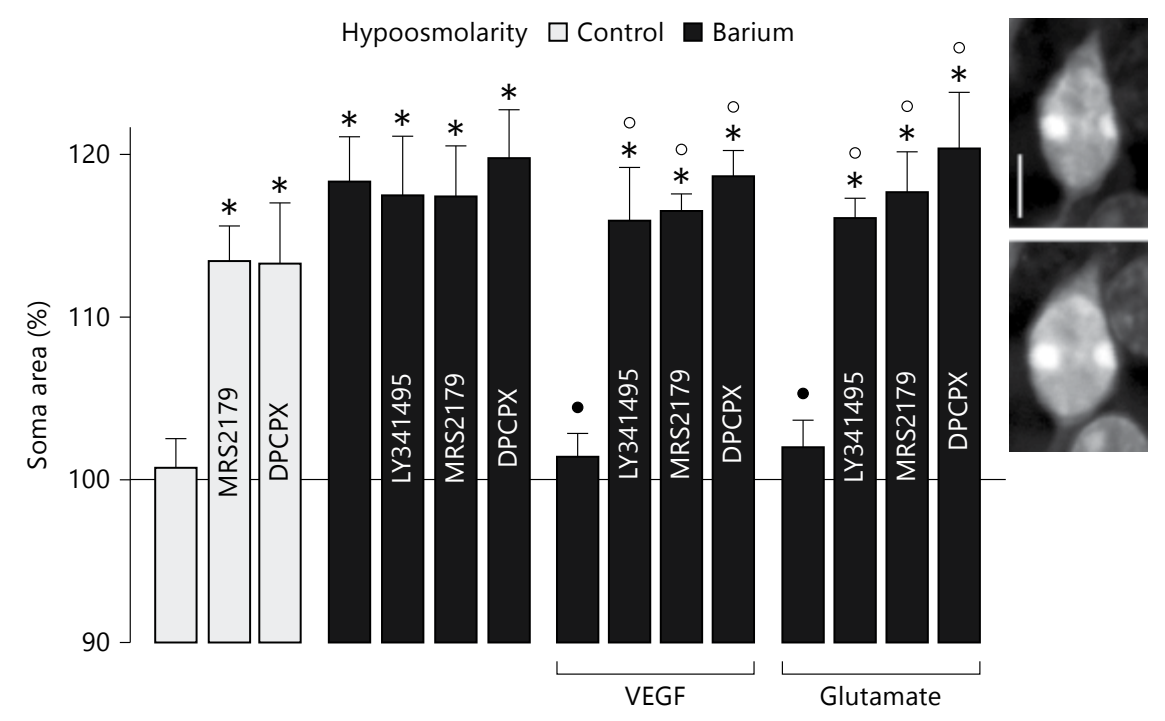

Fig. 1. Receptor-mediated inhibition of osmotic swelling of Müller cell somata in retinal slices from wild-type mice. The cross-sectional area of the somata was measured after a 4-min superfusion of the slices with a hypoosmotic solution (60\% of control osmolarity) in the absence (control) and presence of barium chloride ( $1 \mathrm{mM})$, and is expressed in percent of the soma size measured before osmotic challenge (100\%). In the absence of barium, the selective P2Y $\mathrm{Y}_{1}$ antagonist MRS2179 $(30 \mu \mathrm{M})$ and the adenosine $\mathrm{A}_{1}$ receptor antagonist DPCPX (100 nM) induced swelling of Müller cell somata. The barium-induced swelling was prevented by VEGF $(10 \mathrm{ng} / \mathrm{ml})$ and glutamate $(1 \mathrm{mM})$, respectively. The swelling-inhibitory effects of VEGF and glutamate were abrogated in the presence of the antagonist of group II metabotropic glutamate receptors LY341495 $(100 \mu \mathrm{M}), \mathrm{MRS} 2179(30 \mu \mathrm{M})$ and DPCPX (100 nM), respectively. The images display original records of a dye-filled Müller cell soma obtained before (above) and during (below) superfusion of the hypoosmotic solution in the presence of barium. Bar $=5 \mu \mathrm{m}$. Each bar represents values obtained in 5-14 cells. ${ }^{*} \mathrm{p}<0.05$ : significant swelling induction; ${ }^{\bullet} \mathrm{p}<0.05$ : significant swelling inhibition; ${ }^{\circ} \mathrm{p}<0.05$ : significant inhibition of the agonist effect. within $1 \mathrm{~min}$. The extracellular solution consisted of (in $\mathrm{mM}$ ) 136 $\mathrm{NaCl}, 3 \mathrm{KCl}, 2 \mathrm{CaCl}_{2}, 1 \mathrm{MgCl}_{2}, 10$ HEPES and 11 glucose, adjusted to $\mathrm{pH} 7.4$ with Tris. The hypoosmotic solution $(60 \%$ of control osmolarity) was made up by adding distilled water. Barium chloride (1 mM) was preincubated for $10 \mathrm{~min}$ in extracellular solution before it was applied within the hypoosmotic solution. Blocking substances were preincubated for 15-45 min, and agonists were applied simultaneously with the hypoosmotic solution.

\section{Statistics}

To determine the extent of the swelling of Müller cell somata, the cross-sectional area of the cell bodies was measured off-line using the image analysis software of the laser scanning microscope. For each test, 5-15 cells from 2-3 animals were measured. Data are expressed as means \pm SEM. Statistical analysis was made using Prism (GraphPad Software, San Diego, Calif., USA). Significance was determined by Mann-Whitney $U$ test, and was accepted at $\mathrm{p}<0.05$.

\section{Results}

The swelling of Müller cell somata was investigated by superfusion of freshly isolated retinal slices with a hypoosmotic solution ( $60 \%$ of control osmolarity). As shown in figure 1, hypoosmotic exposure for 4 min did not evoke a significant swelling of glial cell bodies in retinal slices from wild-type mice. However, coadministration of potassium channel-blocking barium ions with the hypoosmotic solution induced significant $(\mathrm{p}<0.05)$ swelling of Müller cell somata. Hypoosmotic exposure of retinal slices also induced a significant ( $\mathrm{p}<0.05)$ swelling of Müller cell somata in the presence of the selective $P 2 Y_{1} R$ antagonist MRS2179 and the $A_{1} A R$ antagonist DPCPX, respectively (fig. 1). The data suggest that swelling of Müller cells under hypoosmotic conditions is normally prevented by autocrine activation of $\mathrm{P} 2 \mathrm{Y}_{1}$ and $\mathrm{A}_{1}$ receptors.

It has been shown that VEGF and glutamate activate the volume-regulatory purinergic signaling cascade in Müller cells $[8,16,17]$. As recently described [18], VEGF and glutamate prevented the barium-induced hypoosmotic swelling of Müller cells (fig. 1). The swelling-inhibitory effects of the receptor ligands were abrogated in the presence of the antagonist of group II metabotropic glutamate receptors LY341495, the selective $\mathrm{P}_{2} \mathrm{Y}_{1} \mathrm{R}$ antagonist MRS2179 and the $\mathrm{A}_{1} \mathrm{AR}$ antagonist DPCPX, respectively (fig. 1) [18]. 
Fig. 2. Various receptor ligands do not inhibit the osmotic swelling of Müller cell somata in retinal slices from $P 2 Y_{1} R^{-/-}(\mathbf{a})$ and $A_{1} A R^{-/-}$mice (b). $W t=$ Wild-type. The cross-sectional area of the somata was measured after a 4-min superfusion of the slices with the hypoosmotic solution in the absence (control) and presence of barium chloride $(1 \mathrm{mM})$, and is expressed in percent of the soma size measured before osmotic challenge (100\%). As comparison, the cross-sectional area of Müller cell somata in retinal slices from wild-type mice was recorded. The following receptor ligands were tested: glutamate (1 $\mathrm{mm})$, VEGF (10 ng/ml), NPY (20 nM) and HBEGF $(20 \mathrm{ng} / \mathrm{ml})$. In addition, triamcinolone acetonide $(50 \mu \mathrm{M})$ was tested. Each bar represents values obtained in 5-13 cells. $* \mathrm{p}<0.05$ : significant swelling induction.

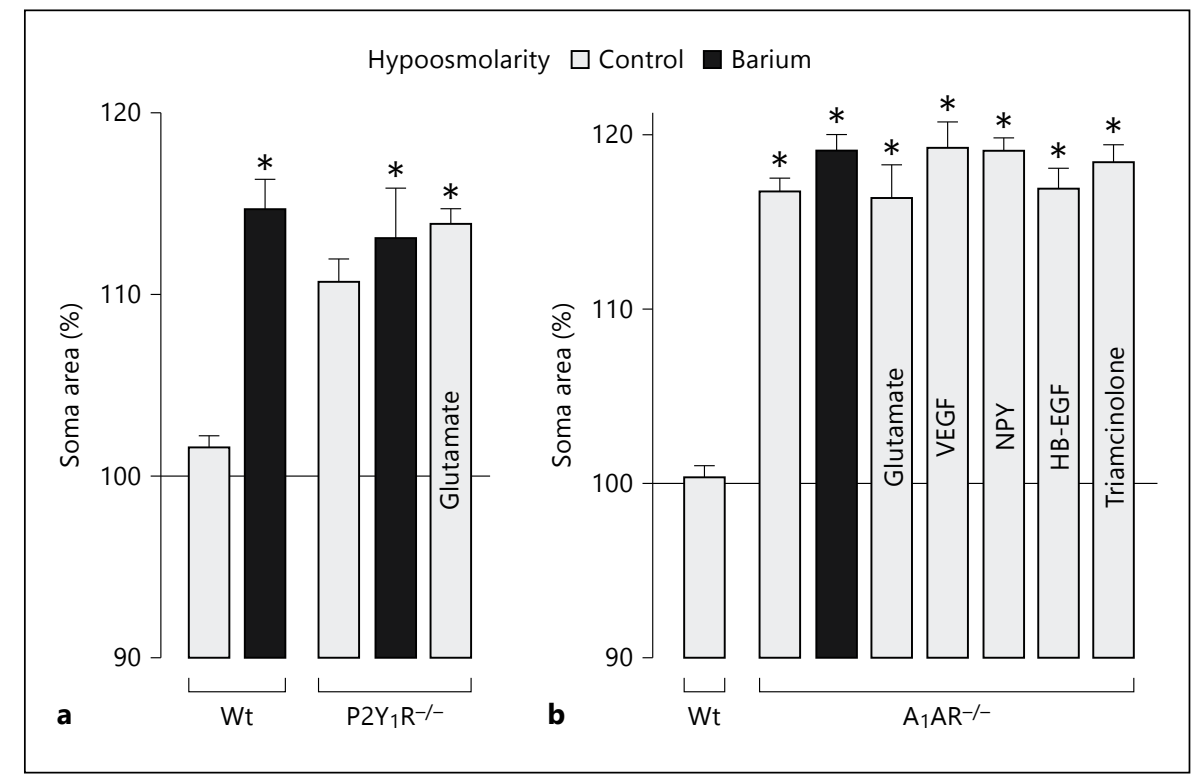

The data suggest that the swelling-inhibitory effect of VEGF is mediated by induction of the release of glutamate, ATP and adenosine, and transactivation of metabotropic glutamate receptors $\mathrm{P} 2 \mathrm{Y}_{1} \mathrm{R}$, and $\mathrm{A}_{1} \mathrm{AR}$, as previously shown in Müller cells of mice and rats $[17,18]$.

To determine whether disruption of the purinergic signaling cascade results in impaired swelling-inhibitory action of VEGF and glutamate in Müller cells, we tested the compounds in retinal slices from $P 2 Y_{1} R^{-/-}$and $A_{1} A R^{-/-}$mice. As previously shown [8], Müller cells of $P 2 Y_{1} R^{-/-}$and $A_{1} A R^{-/-}$mice displayed hypoosmotic swelling under control conditions, which was not observed in cells from wild-type mice (fig. $2 \mathrm{a}, \mathrm{b}$ ). Though glutamate inhibited the osmotic swelling of Müller cells from wildtype mice (fig. 1), it had no swelling-inhibitory effect in cells from $P 2 Y_{1} R^{-/-}$(fig. 2a) and $A_{1} A R^{-/-}$mice (fig. 2b). Likewise, VEGF did not inhibit the osmotic swelling of Müller cells from $A_{1} A R^{-/-}$mice (fig. 2b). In addition, NPY and HB-EGF had no effects on the swelling of Müller cells from $A_{1} A R^{-/-}$mice (fig. 2b); both compounds were previously shown to inhibit the osmotic swelling of Müller cells by activation of the volume-regulatory purinergic signaling cascade $[16,19]$. The glucocorticoid triamcinolone acetonide, which is clinically used for the rapid resolution of retinal edema, had been shown to prevent the hypoosmotic swelling of Müller cells by stimulation of the transporter-mediated release of endogenous adenosine and subsequent activation of $\mathrm{A}_{1} \mathrm{AR}$ [24]. We found that triamcinolone did not inhibit the hypoosmotic swelling of Müller cells from $A_{1} A R^{-/-}$mice (fig. 2b). The data confirm the suggestion that the inhibitory effect of triamcinolone on the cytotoxic swelling of Müller cells is mediated by activation of endogenous adenosine signaling.

It has been demonstrated that the swelling-inhibitory effect of ATP (but not adenosine) in murine Müller cells is dependent on $\mathrm{IP}_{3} \mathrm{R} 2$-mediated intracellular calcium signaling $[7,8]$. As previously shown $[7,8]$, deletion of $\mathrm{IP}_{3} \mathrm{R} 2$ in mice resulted in swelling of Müller cell somata under hypoosmotic conditions (fig. 3), which was not observed in cells of wild-type mice (fig. 1). Adenosine, but not ATP, inhibited the osmotic swelling of Müller cells from $I P_{3} R 2^{-/-}$mice (fig. 3). We found that glutamate and VEGF failed to inhibit the osmotic swelling of Müller cells from $I P_{3} R 2^{-/-}$animals (fig. 3). The data suggest that intracellular calcium signaling mediated by $\mathrm{IP}_{3} \mathrm{R} 2$ is involved in mediating the swelling-inhibitory effects of VEGF and glutamate in murine Müller cells.

\section{Discussion}

It has previously been shown that various receptor ligands including glutamate, VEGF, NPY and HB-EGF inhibit the barium-induced hypoosmotic swelling of Müller cells in control retinas, as well as the osmotic swelling of Müller cells in retinas injured by retinal ischemia-reperfusion and experimental diabetes, for example [16-19]. The inhibition of osmotic swelling induced by receptor ligands is mediated by activation of a volume-regulatory purinergic signaling cascade which includes the auto- 


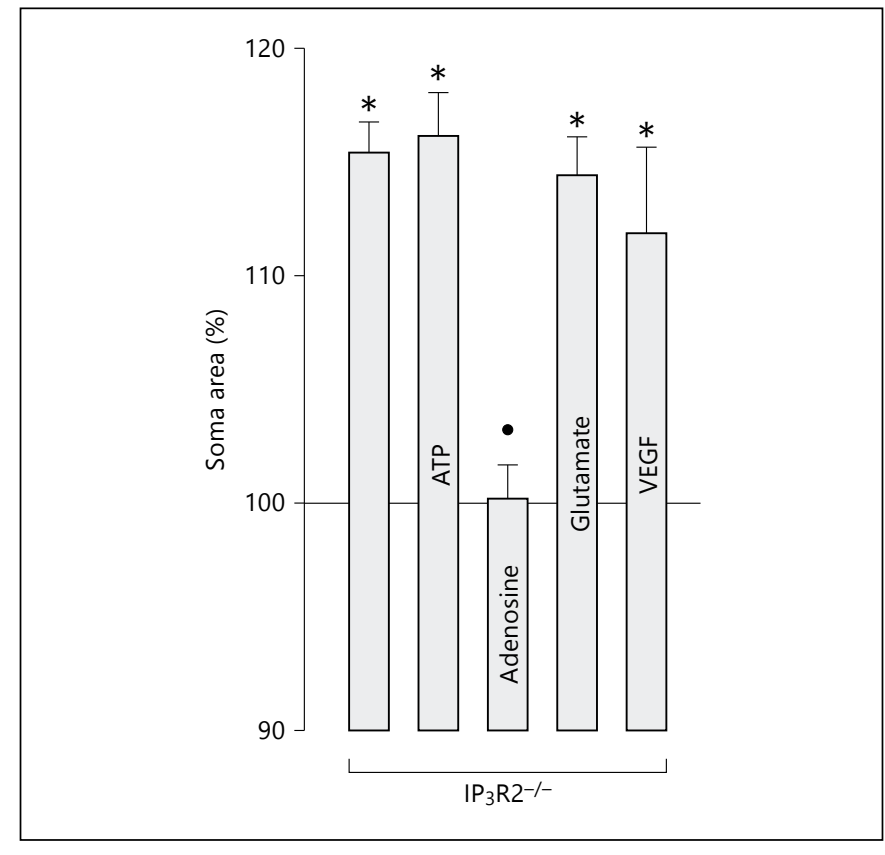

Fig. 3. The osmotic swelling of Müller cell somata in retinal slices of $I P_{3} R 2^{-/-}$mice is inhibited by adenosine $(10 \mu \mathrm{M})$, but not by ATP $(200 \mu \mathrm{M})$, glutamate $(1 \mathrm{mM})$ and VEGF $(10 \mathrm{ng} / \mathrm{ml})$, respectively. The cross-sectional area of the somata was measured after a 4-min superfusion of the slices with the hypoosmotic solution, and is expressed in percent of the soma size measured before osmotic challenge $(100 \%)$. Each bar represents values obtained in 6-15 cells. ${ }^{*} \mathrm{p}<0.05$ : significant swelling induction; ${ }^{\bullet} \mathrm{p}<0.05$ : significant swelling inhibition.

crine release of ATP and adenosine and the activation of $\mathrm{P}_{2} \mathrm{Y}_{1} \mathrm{R}$ and $\mathrm{A}_{1} \mathrm{AR}$ [16-19]. In the present study we show that disruption of this endogenous signaling cascade by deletion of $\mathrm{P}_{2} \mathrm{Y}_{1} \mathrm{R}$ or $\mathrm{A}_{1} \mathrm{AR}$ in mice results in abrogation of the swelling-inhibitory effects of VEGF and glutamate (fig. 2a, b). In addition, we found that NPY and HB-EGF, as well as triamcinolone acetonide, did not inhibit the hypoosmotic swelling of Müller cells from $A_{1} A R^{-/-}$mice (fig. 2b). Furthermore, we show that the swelling-inhibitory effects of glutamate and VEGF require intracellular calcium signaling mediated by $\mathrm{IP}_{3} \mathrm{R} 2$ (fig. 3 ).

The functional consequences of the disrupted glial volume regulation in retinas of $P 2 Y_{1} R^{-/-}, A_{1} A R^{-/-}$and $I P_{3} R 2^{-/-}$mice remain to be determined in future experiments. It has been suggested that neuron-derived signaling molecules such as glutamate regulate Müller cell volume in relation to the momentary neuronal activity $[16$, 17]. Regulation of the Müller cell volume by inhibition of cellular swelling is required because intense neuronal activity in the retina is associated with a decrease in extracellular fluid osmolarity [4], a swelling of retinal neurons

Purinergic Signaling in Glial Volume Regulation
$[17,25]$ and a shrinkage of the extracellular space $[4,25]$; unregulated shrinkage of the extracellular space will cause neuronal hyperexcitation [26].

Disturbance of the transglial water transport was suggested to represent one cause of retinal edema [3]. Intracellular edema of Müller cells was observed in animal models of ischemic and diabetic retinopathies [13, 14]. However, a swelling of Müller cells was rarely observed in retinopathies, suggesting that endogenous mechanisms are present that inhibit osmotic swelling of Müller cells under pathological conditions in situ. Such a mechanism, which inhibits Müller cell swelling despite intracellular edema, may be the activation of the endogenous swellinginhibitory purinergic signaling cascade by receptor ligands such as VEGF, NPY and HB-EGF. It has been shown that, in addition to VEGF [12], the expression of NPY and HB-EGF is elevated in the ischemic retina [19, 27]. Moreover, the $\mathrm{P} 2 \mathrm{Y}$-mediated calcium responsiveness of Müller cells is increased in the ischemic retina [15]. Thus, it is conceivable that VEGF, NPY and HBEGF may inhibit Müller cell swelling under conditions of increased osmotic imbalances in situ.

In the present study we show that deletion of $A_{1} A R$ results in abrogation of the swelling-inhibitory effects of glutamate and VEGF (fig. 2b). We also found that triamcinolone acetonide was ineffective in preventing the swelling of Müller cells in $A_{1} A R^{-/-}$mice (fig. 2b). It has been suggested that the $A_{1} A R$-induced opening of ion channels may facilitate the retinal fluid clearance through Müller cells [15]. Because $\mathrm{A}_{1} \mathrm{AR}$ mediates the swellinginhibitory effects of various different receptor ligands, as well as of triamcinolone [24], agonists of $\mathrm{A}_{1} \mathrm{AR}$ may represent potential agents for the rapid treatment of retinal edema. Further research is required to elucidate the functional significance of the purinergic signaling cascade in the facilitation of transglial fluid transport in edema.

\section{Acknowledgments}

We thank H. Kettenmann (Berlin) for the supply of $A_{1} A R^{-/-}$ mice, and P. Illes and U. Krügel (Leipzig) for the supply of $P 2 Y_{1} R^{-/-}$ mice. This work was supported by grants from the Deutsche Forschungsgemeinschaft (GRK 1097/1 to A.R.; PA615/2-1 to T.P.) and NHLBI (P01 HL080101 to J.C.).

\section{Disclosure Statement}

Each author certifies that he/she has nothing to disclose about commercial sponsorship and no conflicts of interest that may be relevant to the submitted work. 


\section{References}

1 Bresnick GH: Diabetic maculopathy. A critical review highlighting diffuse macular edema. Ophthalmology 1983;90:1301-1317.

-2 Bringmann A, Reichenbach A, Wiedemann P: Pathomechanisms of cystoid macular edema. Ophthalmic Res 2004;36:241-249.

-3 Bringmann A, Pannicke T, Grosche J, et al: Müller cells in the healthy and diseased retina. Prog Retin Eye Res 2006;25:397-424.

4 Dmitriev AV, Govardovskii VI, Schwahn HN, Steinberg RH: Light-induced changes of extracellular ions and volume in the isolated chick retina-pigment epithelium preparation. Vis Neurosci 1999;16:1157-1167.

5 Izumi Y, Kirby-Sharkey CO, Benz AM, et al: Swelling of Müller cells induced by AP3 and glutamate transport substrates in rat retina. Glia 1996;17:285-293.

-6 Gardner TW, Antonetti DA, Barber AJ, LaNoue KF, Levison SW, Penn State Retina Research Group: Diabetic retinopathy: more than meets the eye. Surv Ophthalmol 2002; 47:S253-S262.

7 Lipp S, Wurm A, Pannicke T, et al: Calcium responses mediated by type $2 \mathrm{IP}_{3}$ receptors are required for osmotic volume regulation of retinal glial cells in mice. Neurosci Lett 2009 457:85-88.

$>8$ Wurm A, Lipp S, Pannicke T, et al: Endogenous purinergic signaling is required for osmotic volume regulation of retinal glial cells. J Neurochem 2010;112:1261-1272.

-9 Pannicke T, Iandiev I, Uckermann O, et al: A potassium channel-linked mechanism of glial cell swelling in the postischemic retina. Mol Cell Neurosci 2004;26:493-502.

10 Pannicke T, Uckermann O, Iandiev I, Wiedemann P, Reichenbach A, Bringmann A: Ocular inflammation alters swelling and membrane characteristics of rat Müller glial cells. J Neuroimmunol 2005;161:145-154.
11 Pannicke T, Iandiev I, Wurm A, et al: Diabetes alters osmotic swelling characteristics and membrane conductance of glial cells in rat retina. Diabetes 2006;55:633-639.

12 Rehak M, Hollborn M, Iandiev I, et al: Retinal gene expression and Müller cell responses after branch retinal vein occlusion in the rat. In vest Ophthalmol Vis Sci 2009;50:2359-2367.

13 Kumar B, Gupta SK, Srinivasan BP, et al: Hesperetin rescues retinal oxidative stress, neuroinflammation and apoptosis in diabetic rats. Microvasc Res 2013;87:65-74.

14 Kaur C, Sivakumar V, Yong Z, Lu J, Foulds WS, Ling EA: Blood-retinal barrier disruption and ultrastructural changes in the hypoxic retina in adult rats: the beneficial effect of melatonin administration. J Pathol 2007;212: 429-439.

15 Wurm A, Pannicke T, Iandiev I, et al: Purinergic signaling involved in Müller cell function in the mammalian retina. Prog Retin Eye Res 2011;30:324-342

16 Uckermann O, Wolf A, Kutzera F, et al: Glutamate release by neurons evokes a purinergic inhibitory mechanism of osmotic glial cell swelling in the rat retina: activation by neuropeptide Y. J Neurosci Res 2006;83:538-550.

17 Wurm A, Pannicke T, Wiedemann P, Reichenbach A, Bringmann A: Glial cell-derived glutamate mediates autocrine cell volume regulation in the retina: activation by VEGF. J Neurochem 2008;104:386-399.

18 Brückner E, Grosche A, Pannicke T, Wiedemann P, Reichenbach A, Bringmann A: Mechanisms of VEGF- and glutamate-induced inhibition of osmotic swelling of murine retinal glial (Müller) cells: indications for the involvement of vesicular glutamate release and connexin-mediated ATP release. Neurochem Res 2012;37:268-278.

19 Weuste M, Wurm A, Iandiev I, Wiedemann P, Reichenbach A, Bringmann A: HB-EGF: increase in the ischemic rat retina and inhibition of osmotic glial cell swelling. Biochem Biophys Res Commun 2006;347:310-318.
20 Wurm A, Lipp S, Pannicke T, et al: Involvement of $A_{1}$ adenosine receptors in osmotic volume regulation of retinal glial cells in mice. Mol Vis 2009;15:1858-1867.

21 Fabre JE, Nguyen M, Latour A, et al: Decreased platelet aggregation, increased bleeding time and resistance to thromboembolism in $\mathrm{P}_{2} \mathrm{Y}_{1}$-deficient mice. Nat Med 1999;5: 1199-1202.

22 Li X, Zima AV, Sheikh F, Blatter LA, Chen J: Endothelin-1-induced arrhythmogenic $\mathrm{Ca}^{2+}$ signaling is abolished in atrial myocytes of inositol-1,4,5-trisphosphate $\left(\mathrm{IP}_{3}\right)$-receptor type 2-deficient mice. Circ Res 2005;96:1274-1281.

23 Sun D, Samuelson LC, Yang T, et al: Mediation of tubuloglomerular feedback by adenosine: evidence from mice lacking adenosine 1 receptors. Proc Natl Acad Sci USA 2001;98: 9983-9988.

24 Uckermann O, Kutzera F, Wolf A, et al: The glucocorticoid triamcinolone acetonide inhibits osmotic swelling of retinal glial cells via stimulation of endogenous adenosine signaling. J Pharmacol Exp Ther 2005;315:10361045.

25 Uckermann O, Vargová L, Ulbricht E, et al Glutamate-evoked alterations of glial and neuronal cell morphology in the guinea-pig retina. J Neurosci 2004;24:10149-10158.

26 Dudek FE, Obenhaus A, Tasker JG: Osmolality-induced changes in extracellular volume alter epileptiform bursts independent of chemical synapses in the rat: importance of non-synaptic mechanisms in hippocampal epileptogenesis. Neurosci Lett 1990;120:267270.

27 Yoon HZ, Yan Y, Geng Y, Higgins RD: Neuropeptide $\mathrm{Y}$ expression in a mouse model of oxygen-induced retinopathy. Clin Exp Ophthalmol 2002;30:424-429. 